\title{
Funding for the Soviet health service
}

\author{
MICHAEL RYAN
}

For the most famous detective in English literature a vital clue was once provided by the fact that a dog did not bark at night: " "That was the curious incident,' remarked Sherlock Holmes." In a broadly comparable way one important aspect of the Soviet polity could be deduced from the general absence of published information, let alone critical comment, about the proportion of national wealth devoted to expenditure on the social welfare services. This topic has now ceased to be taboo-at least in respect of the health service.

In the past it was official practice to refer simply to year on year increases in the absolute figures for expenditure on the service or to increases in the same figures expressed on a per caput basis, thus creating favourable propaganda. So the new health minister, Yevgeniy Chasov, almost certainly made history in his own country when he set expenditure against total national income. Incidentally, this particular indicator became the acid test of any British government's generosity largely as a result of its salience in the massively authoritative Report of the Committee of Inquiry into the Cost of the National Health Service, a government blue book, which was published in 1956.

It does not detract from the importance of Chasov's words to point out that the need to improve public services for the ordinary citizen has been recognised in the context of perestroika, the comprehensive social and economic reconstruction that the Soviet leadership aims at achieving. That recognition was attested fairly openly by Mikhail Gorbachev in his lengthy report to the January 1987 plenum of the party's central committee. "The social goals of the economy in the past few five-year plan periods were obviously diluted," said the general secretary, "and there emerged a sort of deafness to social issues." responsible. Thus at the outset of an interview published in the journal Literary Gazette he quoted his authorisation, so to say, for claiming additional expenditure. ${ }^{1}$

The minister first referred to existing levels of spending, pointing out that the percentage of national income assigned to health care "is relatively small and is showing a tendency to decline." In 1970, he said, the figure had been $4 \cdot 1 \%$; today it stands at $4 \cdot 0 \%$ and by 1990 , if the present level of funding continues, it will have fallen to $3.9 \%$.

As it happens the first figure that he cites can be corroborated if data are brought together from different sections of the annual abstract of statistics. That source makes it possible to construct a time series for the quarter century $1960-85$ and to record several crucially important qualifications and explanations.

The initial point that comes to light in table I represents an accounting convention; the small public spending on physical culture is added to that on the health service to form a single entry. The second is that the sums allocated through the state budget are supplemented to a substantial extent from other public sources. These embrace a wide range of organisations and enterprises (to use official terminology) which provide health care and other facilities for their workforce out of funds at their own disposal. The table shows that the aggregate of these non-coordinated commitments came to bulk larger over the quarter century; their share rose appreciably from $15 \cdot 8 \%$ to $22 \cdot 1 \%$ of the total.

Another matter to which the table draws attention is the measure of national income that Soviet economic statisticians conventionally employ. Since it relates only to "the sectors of the sphere of material production," excluding the value of "non-productive" services, it is more appropriately termed net material product. This point has an obvious implication for cross national comparative studies.

TABLE I-Expenditure on health service and physical culture, 1960-85

\begin{tabular}{cccccc}
\hline $\begin{array}{c}\text { Spending under } \\
\text { state budget } \\
\text { (roubles (billions)) }\end{array}$ & $\begin{array}{c}\text { Spending under state budget } \\
\text { and other public sources } \\
\text { (roubles (billions)) }\end{array}$ & $\begin{array}{c}\text { Net material product } \\
\text { (NMP) } \\
\text { (roubles (billions)) }\end{array}$ & $\begin{array}{c}\text { State budget expenditure } \\
\text { as \% of NMP }\end{array}$ & $\begin{array}{c}\text { State budget and other public funding } \\
\text { as \% of NMP }\end{array}$ \\
\hline 1960 & 4.8 & 5.7 & 145.0 & 3.31 & 3.93 \\
1970 & 9.3 & 11.8 & 289.9 & 3.21 & 4.07 \\
1975 & 11.5 & 14.6 & 363.3 & 3.17 & 3.11 \\
1980 & 14.8 & 19.0 & 462.2 & 3.20 & 3.91 \\
1985 & 17.6 & 22.6 & 577.7 & 3 & \\
\hline
\end{tabular}

Source: Narodnoe khozyaistvo SSSR for 1970:533; for 1985:409,559,561.

\section{Record of parsimony}

A few months later those words were invoked by Chasov as the preface to an unparalleled exposé of fundamental defects in the human and capital resources of the service for which he is

\footnotetext{
Centre of Russian and East European Studies, University College of Swansea, Swansea SA2 8PP
}

MICHAEL RYAN, PHD, lecturer in politics and Russian studies

\section{Structure of the budget}

Since the institutional development of health care systems has varied from country to country, a comparative analysis would also need to take some account of the scope of the scheme provided. A key question that arises is: do the expenditure data include or exclude the cost of what can be termed environmental health programmes? In postwar Britain these were not brought within the ambit of the NHS legislation, but in the USSR they form an integral feature of the health service.

Lacking strong traditions of public accountability, the Soviet 
authorities publish only the most exiguous breakdown of social welfare expenditures on an annual basis. Even so, from the latest data (relating to 1985) calculations can be made that cast some light on dark places.

From table II it emerges that "curative-prophylactic establishments"- that is, the personal medical services-account for the lion's share of current spending, whereas "sanitary-prophylactic establishments and measures"-that is, environmental health programmes-take only $3.8 \%$. Physical culture accounts for insignificant amounts: $0.7 \%$ of the relevant current spending in 1985. Although the source does not subdivide capital expenditure in the same way, the construction of new hospitals and policlinics probably absorbs a large proportion of it.

TABLE II-Breakdown of state budget expenditure on health service and physical education, 1985

\begin{tabular}{lcc}
\hline & Roubles (millions) & $\%$ \\
\hline Total expenditure & 17611 & 100 \\
Capital allocations & 1103 & $5 \cdot 8$ \\
Current expenditure on: & 15214 & $86 \cdot 4$ \\
Curative-prophylactic establishments & 672 & $3 \cdot 8$ \\
Sanitary-prophylactic establishments and measures & 118 & $0 \cdot 7$ \\
Physical culture & 594 & 3.4 \\
Residual within current expenditure & & \\
\hline
\end{tabular}

Source: Narodnoe khozyaistvo SSSR v 1985g:563.

There is also a sizable residual item and the source provides no explanation of this. But even when this sum has been added in, the proportion of Soviet net material product that is devoted specifically to personal medical care through the state budget still does not exceed $3 \%$.

\section{Harsh realities}

Severely compounding the consequence of underfunding is a long familiar feature of the country's economic planning systemnamely, its emphasis on purely quantitative indicators. "We have striven to achieve the planned number of hospital beds," Chasov told his interviewer, "not caring whether they conform to the requirements of medical technology or even sanitary standards." As an example he pointed out that according to the norm there should be 7 square metres of space per hospital bed but that in practice only $4 \cdot 2$ were provided.

Equally revealing details of this type had already been given by the minister to a specialist audience in a speech which largely pre-empted the contents of his interview. ${ }^{2}$ Thus he had said that the normal cost of a new hospital bed in the current five year planning period had been fixed at 19 thousand roubles, whereas it ranged between 40 and 80 thousand in several neighbouring socialist countries. When a new hospital is commissioned a mere $15 \%$ of its total cost is earmarked for technical equipment, as against $40 \%$ in eastern Europe (the remaining $85 \%$ goes on bricks and cement).

Such is their sense of compulsion to achieve numerical targets that the republics and local soviets frequently resort to adapting dwelling houses and hostels for hospitals, as well as constructing units of unconventional design at appreciably lower costs than those set by the planners. In the central Asian republic of Tadzhikistan a unit had been constructed for less than five thousand roubles per bed and that, Chasov drily noted, represented the cost of providing a stall on a cattle farm.

It is a familiar point that the most backward conditions generally obtain in the rural hospitals, policlinics, and ambulatories. Improbable as it may sound, the minister told his audience that "in only $35 \%$ of the rural district hospitals of the country is there a supply of hot water and in $27 \%$ there is no sewerage system and in $17 \%$ no running water."

In the capital a striking contradiction was identified by Literary Gazette's interviewer: although patients make the journey there from all corners of the union, Moscow women will go anywhere to avoid giving birth in local maternity homes. Chasov replied in the true spirit of glasnost: "However unpleasant it may be to admit this, Moscow's health service is in a most serious condition." Among other deficiencies its maternity homes were in a "calamitous state": out of 33, only 12 conformed to current sanitary standards.

The minister also broached several other highly important issues, including the work of medical research institutes, and he outlined a radical reform of medical education. One statement, however, may be thought to transcend all else: Dr Chasov made what amounts to a public bid for a truly massive increase in funding. "According to our preliminary calculations," he said, "by the year 2000 allocations for health protection ought to amount to $8 \%$ of national income." This must mean if his statement of required spending were accepted that the proportion of national wealth devoted to the Soviet health service would be doubled.

\section{Comment}

If Chasov's statements are viewed in a purely historical light their main importance is surely that they mark the beginning of a new chapter. From the early 1930 s until recently successive ministers of health did not speak out publicly on the underlying problems of the service for which they were answerable-and with good reason. As senior party members they would hardly need reminding of pragmatic considerations bearing on the art of self preservation (especially relevant during Stalin's tyranny), or of the intellectual constraints which were imposed by the conventional dialectic of Soviet socialism.

On a political reading, however, it may be doubted whether the health service will be permitted to acquire a much larger slice of the national cake. Competing demands from other lobbies, most obviously the military, seem unlikely to diminish in the short term and no great accession to the health minister's bargaining power can be easily envisaged. A final consideration concerns the absence of an influential constituency. Although many doctors presumably welcome Chasov's advocacy, they lack the opportunity to show their collective support with pressure group activities, which would constitute a combative campaign for a more adequately resourced health service.

I thank Dr Ian Jeffries for his helpful comments.

\section{References}

1 Galaeva A. (Intervyu vela.) Vrach na poroge III tysyacheletiya. Literatumaya Gazeta 1987;29 Aprelya:11.

2 Betlugin I. V Ministerstve Zdravookhraneniya SSSR: Na perelome. Meditsinskaya Gazeta 1987;25 Marta:1.

\section{Is there any evidence that wearing braces causes cancer of the nipple in men?}

Paget's disease of the nipple is rare in men. ${ }^{1}$ No predisposing factors are known, and certainly there is no evidence that trauma of any sort results in Paget's disease of the female breast, let alone the male. Carcinoma of the breast itself may, of course, invade the nipple, but cancer of the male breast accounts for only $1 \%$ of all malignant diseases of the breast. The only factors associated with increased risk of breast cancer in men are previous exposure to irradiation ${ }^{2}$ and perhaps hyperoestrogenism. Thus patients with Klinefelter's syndrome have an incidence of breast cancer that approaches the risk for women. Again, there is no evidence of an association between trauma and breast cancer either in the male breast or in the much more closely studied cancer of the female breast. To sum up, the answer to this question is no.-HAROLD ELLIS, professor of surgery, London.

1 Lanser HA, Moschell SL. Paget's disease of the male breast. I Am Acad Dermatol 1982;7:393-6. 2 Greene MH, Goedert JJ, Bech-Hansen NT. Radiogenic male breast cancer with in vitro sensitivity to ionizing radiation and bleomycin. Cancer Investigation 1983;1:379-86. 